\title{
Unusual discovery of the 'Australian Firebeetle' Merimna atrata on an older postfire area
}

\author{
Anke Schmitz and Helmut Schmitz \\ Institute of Zoology, University of Bonn, Meckenheimer Allee 169, 53115 Bonn, Germany. \\ Email: ankeschmitz@uni-bonn.de; h.schmitz@uni-bonn.de
}

KEYWORDS: Australian firebeetle, forest fire, pyrophilous insects, infrared reception

\section{INTRODUCTION}

The 'Australian Firebeetle' Merimna atrata (Gory \& Laporte, 1837) is endemic to Australia and to southern parts of Papua New Guinea (Hawkeswood 2007; Schmitz et al. 2015). As indicated by its common name, this uniform black beetle in the jewel beetle family Buprestidae is attracted to ongoing bush fires and starts to invade the freshly burnt area immediately after the active fire has gone out (Tepper 1887; Poulton 1915; Schmitz and Schmitz 2002). The reason for this pyrophilous behaviour is based on the special food source of the xylophagous larvae that can only develop in severely fire scorched trees and shrubs of the family Myrtaceae (Hawkeswood and Peterson 1982; Hawkeswood 2007; Kitchin 2009; Schmitz et al. 2015). Consequently, the adult beetles of both sexes approach fires and meet on the freshly burnt areas. The early arrival of $M$. atrata on burnt areas confers the clear advantage of smoke and heat emitted by hotspots such as burning or glowing wood and hot ashes, which keep away competitors like other wood boring insects as well as predators like birds and lizards. However, an accidental landing on a hot surface may be life threatening for a small insect. To cope with this danger, $M$. atrata has developed abdominal infrared receptors as an early warning system for hot spots (Schmitz et al. 2000; Schmitz et al. 2001; Hinz et al. 2018).

After the fire, the hot spots gradually go out and, therefore, the protective shield build by heat and smoke disappears within a few days. Hence, predators of M. atrata, such as the Australian Magpie (Cracticus tibicen) become increasingly present. Consequently, $M$. atrata disappears within three to four days after the fire and, after about five days, no more beetles can be found on the cool postfire area. This has quantitatively been documented for a small burnt area close to Yanchep National Park, Western Australia in 2014 (Schmitz et al. 2015). Furthermore, the authors have inspected more than 50 older postfire areas in the Perth Metropolitan area and in the adjacent Perth Hills in the last 15 years and have never found M. atrata in burnt areas more than five days old.

Thus, it was surprising that in January 2020 a noteworthy number of $M$. atrata was found in a postfire area more than one month after the fire. This unusual observation is reported here and possible reasons for the prolonged stay of the firebeetles are discussed.

\section{MATERIALS AND METHODS}

\section{INVESTIGATION AREA}

M. atrata was found in January 2020 on a burnt area created by the 'Yanchep Fire' that burnt in the beginning of December 2019. This large bushfire started on 11 December next to Wanneroo Road, about $1 \mathrm{~km}$ south of the intersection with Yanchep Beach Road. Within five days, the fire travelled $25 \mathrm{~km}$ in a north-westerly direction up to Barragoon Road south of Guilderton. In total, an area of 13,000 hectares was burnt. In Yanchep National Park, the fire burnt the forest on the western bank of Lake Loch McNess. In this area, the swampy lakeshore is covered with Swamp Paperbarks (Melaleuca rhaphiophylla) followed by a eucalyptus forest with River Gum (Eucalyptus rudis) and Tuart (E. gomphocephala). The small spot where we found the beetles was located inside the burnt forest on the western bank of the lake, opposite the camping and recreation area on the unburnt eastern bank of Loch Mc Ness. Where the beetles were discovered, the 'Ghost House Trail' runs very close to the lakeshore and the fire had burnt into the subterranean roots of the Swamp Paperbarks so that many trees had fallen over. From time to time small amounts of smoke emerged out of the rootholes. The investigation area bordered directly on the Melaleuca girdle and had a size of about $50 \mathrm{x}$ $20 \mathrm{~m}$ (GPS coordinates $31.54404^{\circ} \mathrm{S}, 115.67713^{\circ} \mathrm{E}$ ). Six large eucalyptus trees in the area provided preferential landing sites for the beetles (Figure 1). 


\section{COLLECTION AND DOCUMENTATION}

$M$. atrata was observed and captured on 8 days in the period from 13-27 January 2020. Beetles were collected from the six larger trees by hand or - when resting in the ashes on the ground around the trees - by net. All captured beetles were retained and used for further morphological and neuroanatomical investigations (Collecting Permit issued by DBCA, see Acknowledgements). Thus, potential double counting was avoided.

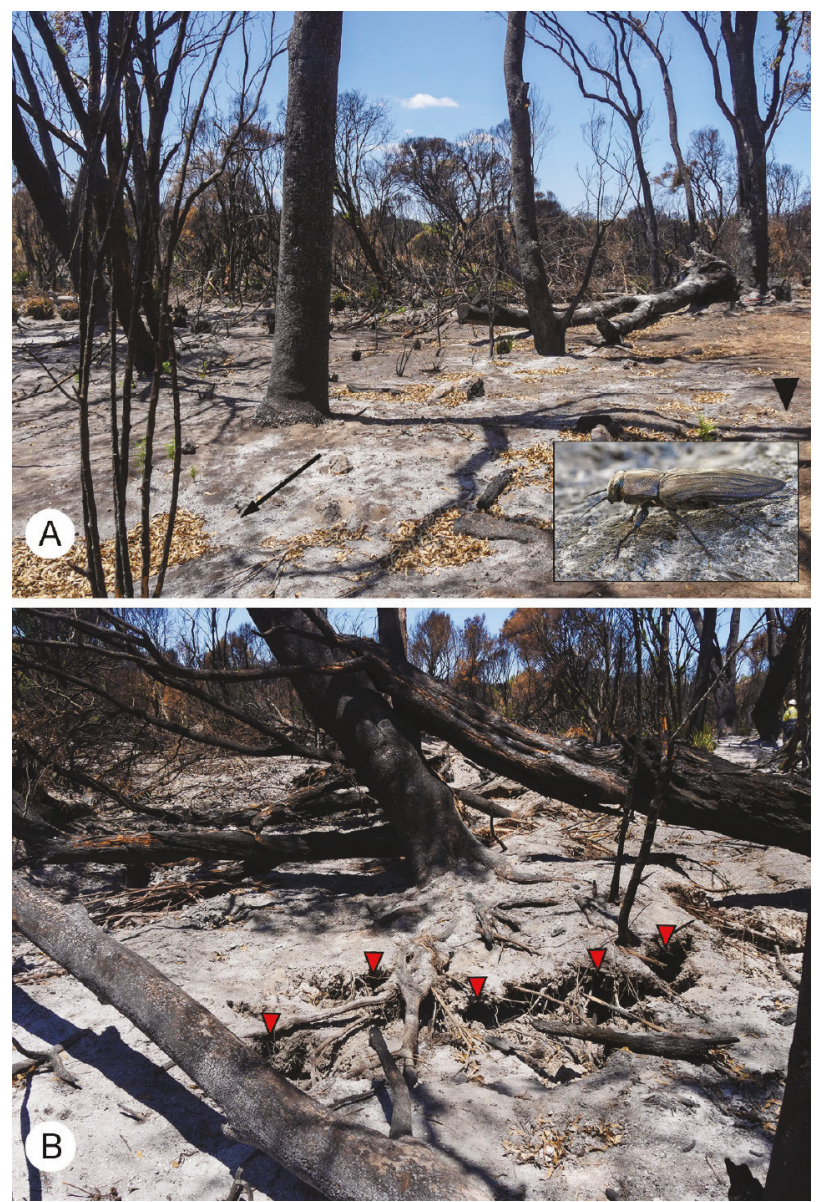

FIGURE 1 Burnt investigation area where $M$. atrata was found: A) Southerly view showing five of the six larger eucalyptus trees used by the beetles as preferred landing sites. In the background, the lakeside with the girdle of heavily burnt swamp paperbarks is visible. Most of the paperbarks had fallen down because the fire continued to burn underground in the roots. In the lower right corner, the Ghost House Trail is visible (arrowhead) representing the western border of the area. Arrow points towards tree No. 1, about $20 \mathrm{~m}$ away. Inset in the lower right corner shows a Merimna sitting on a burnt log. B) The eucalyptus tree No. 1 that attracted most beetles. This tree was knocked over by a fallen paperbark and bordered the northern part of the observation area. Consequently, the root plate was partly lifted creating many holes (arrowheads). Smoke and hot air emitted from roots burning underground emerged from the holes.

\section{TEMPERATURE MEASUREMENTS}

Surface temperatures of the visible inner walls of the holes in ground around tree No. 1 (see Fig. 1B) were measured with a handheld infrared thermometer (Ryobi Infrared Thermometer RIT310).

\section{RESULTS AND DISCUSSION}

Over the observation period a total of $30 \mathrm{M}$. atrata was caught in the investigation area (Figure 1, Table 1). About a dozen additional beetles were also sighted. However, because these beetles were not captured, it cannot be ruled out that some beetles were counted twice. Occasionally a few females were observed diving with their abdomen deep into the ash, presumably in an attempt to deposit eggs under the bark of hidden roots of nearby trees. Copulation attempts by males were also seen. Most beetles were seen and caught on Tree No. 1 or close to this tree on the ash covered ground (Figure 1B). On one day, six beetles could be observed simultaneously on this tree for some minutes.

To confirm that the beetles occurred only on the observation site, inspection rounds in the burnt eucalyptus forest adjacent to the investigation area were made 2-3 times on each observation day. Rounds were made parallel to the investigation area about $30-40 \mathrm{~m}$ to the west of the 'Ghost House Trail', which represented the western boundary of the investigation area. During these 20 rounds only four beetles were observed. These beetles were rather furtive and flew away when the observer approached. Farther away from the investigation area (e.g. when approaching the observation site from the Yanchep Beach Road) we never saw any beetles in the burnt forest. In contrast, the beetles in the investigation area were more or less stationary. Males flew from tree to tree in search for females, and a few females deposited their eggs. In principle, beetles showed the same behaviour as observable on freshly burnt areas (Schmitz et al. 2015), though with a reduced intensity. As a result, the prolonged presence of $M$. atrata on the inspected area more than a month after the fire was rather unusual.

TABLE 1 Beetles captured on the survey area.

\begin{tabular}{lll} 
Date & $\begin{array}{l}\text { No. of beetles } \\
\text { captured }\end{array}$ & $\begin{array}{l}\text { Observation } \\
\text { Period }\end{array}$ \\
\hline 13 January 2020 & 2 & $10: 30-14: 00$ \\
15 January 2020 & 3 & $10: 00-14: 00$ \\
16 January 2020 & 7 & $10: 15-14: 15$ \\
18 January 2020 & 4 & $10: 00-14: 15$ \\
19 January 2020 & 2 & $10: 00-14: 00$ \\
25 January 2020 & 8 & $11: 00-14: 30$ \\
26 January 2020 & 3 & $10: 30-14: 00$ \\
27 January 2020 & 1 & $10: 30-14: 15$
\end{tabular}


There are several possible explanations for why $M$. atrata persisted at this site so long after the fires had passed. First, the 'Yanchep Fire' burnt for five days with a high intensity and is likely to have attracted a large number of beetles. These beetles found favourable conditions in the freshly burnt area and, therefore, stayed as long as burning or smouldering Eucalyptus wood was present. With high sensitivity, M. atrata can smell odours characteristic of burning gum wood, such as eucalyptol, and also some other volatile organic compounds (VOCs) characteristic of burning wood more generally, such as furfural and 2-methoxyphenol (Paczkowski 2018). This acute sense of smell enables $M$. atrata to detect and select eucalyptus fires while avoiding those in banksia forests or in pine plantations (pers. obs.). Once in the freshly burnt area, the smoke profoundly alters the behaviour of the beetles, who stay in the burnt area, show nearly no escape behaviour, and engage in reproductive activities. As yet there is no evidence for sex pheromones in $M$. atrata. Therefore, it is possible that the smoke of burning gum wood has — at least partly - taken over the role of a pheromone system in attracting both sexes together for reproduction (Schmitz et al. 2015). We suggest that most probably, the small amount of smoke still emerging from underground was the reason for the prolonged stay of beetles at the site. The smoke given off by the burning roots of swamp paperbarks and flooded gums potential breeding trees for this species - would likely have contained the right blend of odorants to attract the beetles. This scenario is especially supported by the pushed away tree No. 1. Smoke escaped permanently out of the openings around the lifted root plate. Although the smoke was mostly hard to see, temperature measurements of the inner walls of the openings around the tree always yielded temperatures of about $100^{\circ} \mathrm{C}$, indicating a constant flow of gases from combustion emitted by the smouldering roots. This tree was clearly favoured by the beetles.

In summary, the special conditions in and around the investigation area made this spot into a small 'habitat island' of favourable conditions for the Australian firebeetle long after the fire. This likely continued to attract new beetles from the closer surroundings that became aware of the smell of burning for as long as the site continued to smoke.

\section{ACKNOWLEDGEMENTS}

We are indebted to the Department of Biodiversity, Conservation and Attractions (DBCA) in WA for issuing the Fauna Taking Licences No. FO25000232 from $06 / 01 / 2020$. Brian Inglis, Clayton Sanders and Leigh Sage from the Parks and Wildlife Service of DBCA in Wanneroo permitted access to the burnt areas and supported our fieldwork. We thank two anonymous referees for their helpful comments.

\section{REFERENCES}

Hawkeswood, T.J. (2007). Review of the biology of the genus Merimna Saunders, 1868 (Coleoptera: Buprestidae). Calodema 9: 12-13.

Hawkeswood, T.J. and Peterson, M. (1982). A review of the larval host records for Australian jewel beetles (Coleoptera: Buprestidae). Victorian Naturalist 99: 240-251.

Hinz, M., Klein, A., Schmitz, A. and Schmitz, H. (2018). The impact of infrared radiation in flight control in the Australian "firebeetle" Merimna atrata. PLOS ONE 13: e0192865. doi: 10.1371/journal.pone.0192865

Kitchin, D.R. (2009). Notes on the biology of Merimna atrata (Gory \& Laporte) (Coleoptera: Buprestidae). Australian Entomologist 36: 1-2.

Paczkowski, S. (2018). Wood Fire Detection by imitating Beetle Olfaction with Gas Sensors. Current Trends in Entomology: CTEZS-105: 000005. doi: 10.29011/CTEZS-105.000005.

Poulton, E.B. (1915). The habits of the Australian buprestid "fire-beetle" Merimna atrata, Lap. et Gory. Transactions of the Entomological Society of London Part 1 (Proceedings): 3-4.

Schmitz, A., Schneider, E.S. and Schmitz, H. (2015). Behaviour of the Australian 'fire-beetle' Merimna atrata (Coleoptera: Buprestidae) on burnt areas after bushfires. Records of the Western Australian Museum 30(1): 1-11. doi: 10.18195/ issn.0312-3162.30(1).2015.001-011.

Schmitz, H. and Schmitz, A. (2002). Australian fire-beetles. Landscope Spring 2002: 36-41.

Schmitz, H., Schmitz, A. and Bleckmann, H. (2000). A new type of infrared organ in the Australian" firebeetle" Merimna atrata (Coleoptera: Buprestidae). Naturwissenschaften 87: 542-545. doi: 10.1007/ s001140050775.

Schmitz, H., Schmitz, A. and Bleckmann, H. (2001). Morphology of a thermosensitive multipolar neuron in the infrared organ of Merimna atrata (Coleoptera, Buprestidae). Arthropod Structure and Development 30: 99-111.

Tepper, J.G.O. (1887). Common Native Insects of South Australia: A Popular Guide to South Australian Entomology. E.S. Wigg \& Son, Adelaide, 1-46. doi: 10.1016/s1467-8039(01)00028-7

MANUSCRIPT RECEIVED 22 JUNE 2020; ACCEPTED 12 OCTOBER 2020. 